\title{
ATM-depletion in breast cancer cells confers sensitivity to PARP inhibition
}

\author{
Maria Saveria Gilardini Montani ${ }^{1}$, Andrea Prodosmo ${ }^{2}$, Venturina Stagni ${ }^{3,4}$, Dania Merli ${ }^{1}$, Laura Monteonofrio ${ }^{2}$, \\ Veronica Gatti ${ }^{2}$, Maria Pia Gentileschi ${ }^{2}$, Daniela Barilà, ${ }^{3,4}$ and Silvia Soddu ${ }^{2^{*}}$
}

\begin{abstract}
Background: Mutations in the DNA damage response (DDR) factors, breast cancer 1 (BRCA1) and BRCA2, sensitize tumor cells to poly(ADP-ribose) polymerase (PARP) inhibitors. The ataxia telangiectasia mutated (ATM) kinase is a key DDR protein whose heterozygous germline mutation is a moderate-risk factor for developing breast cancer. In this study, we examined whether ATM inactivation in breast cancer cell lines confers sensitivity to PARP inhibitors.

Methods: Wild-type BRCA1/2 breast cancer cells (i.e., MCF-7 and ZR-75-1 lines) were genetically manipulated to downregulate ATM expression then assayed for cytostaticity/cytotoxicity upon treatment with PARP inhibitors, olaparib and iniparib.

Results: When ATM-depleted cells and their relative controls were treated with olaparib (a competitive PARP-1/2 inhibitor) and iniparib (a molecule originally described as a covalent PARP-1 inhibitor) a different response to the two compounds was observed. ATM-depletion sensitized both MCF-7 and ZR-75-1 cells to olaparib-treatment, as assessed by short and long survival assays and cell cycle profiles. In contrast, iniparib induced only a mild, ATM-dependent cytostatic effect in MCF-7 cells whereas ZR-75-1 cells were sensitive to this drug, independently of ATM inactivation. These latest results might be explained by recent observations indicating that iniparib acts with mechanisms other than PARP inhibition.
\end{abstract}

Conclusions: These data indicate that ATM-depletion can sensitize breast cancer cells to PARP inhibition, suggesting a potential in the treatment of breast cancers low in ATM protein expression/activity, such as those arising in mutant ATM heterozygous carriers.

Keywords: Breast cancer, ATM, PARP inhibitors, Olaparib, Iniparib

\section{Background}

In the past few years, much effort has been made towards identifying chemotherapeutic compounds targeting the core components of DDR and repair pathways, which are frequently altered in tumor cells. The goal for these new anti cancer strategies would be to take advantage of the cancer cell defects in repairing their own DNA and use it as an Achille's heel to enhance therapeutic indices, with limited normal tissue toxicity. Among these new compounds, PARP inhibitors have been shown to be highly lethal to tumor cells with deficiencies in DDR factors such as BRCA1 or BRCA2 [1,2]. The mechanism

\footnotetext{
* Correspondence: soddu@ifo.it

${ }^{2}$ Experimental Oncology, Regina Elena National Cancer Institute, Via Elio Chianesi, 53-00144 Rome, Italy

Full list of author information is available at the end of the article
}

underlining this approach is based on the concept of synthetic lethality first described in the fruit fly Drosophila $[3,4]$ and subsequently translated into an efficient method to design novel anticancer drugs $[5,6]$. Synthetic lethality centers on targeting two separate molecular pathways that are nonlethal when disrupted individually, but are lethal when inhibited simultaneously [7].

In the case of PARP inhibitors and BRCA1/2 mutations, the two molecular pathways whose concomitant inactivation promotes a synthetic lethal relationship are the basic excision repair (BER), responsible for the repair of singlestrand DNA breaks (SSBs), and the homologous recombination (HR), that repairs double strand DNA breaks (DSBs). In particular, BER inactivation by PARP inhibitors induces SSBs that during DNA replication cause lethal breaks in both DNA strands. In normal cells, the latter

\section{Biomed Central}

(c) 2013 Gilardini Montani et al.; licensee BioMed Central Ltd. This is an open access article distributed under the terms of the Creative Commons Attribution License (http://creativecommons.org/licenses/by/2.0), which permits unrestricted use, distribution, and reproduction in any medium, provided the original work is properly cited. 
breaks are repaired by HR, but in tumor cells in which HR is defective, such as in the presence of BRCA1/2 mutations, DSBs are not repaired and their accumulation causes cell death $[1,2]$. These original observations have led to PARP inhibitors entering subsequent phase II clinical trials in breast and ovarian cancer patients, with or without BRCA mutations [8-10]. At present, the data from clinical studies are not as favorable as promised by the preliminary results $[11,12]$. Though there might be various causes explaining the clinical performance of the different PARP inhibitors, one of the challenging issues remains on how to identify those patients most receptive to these treatments [13].

Deficiency in several DDR factors other than BRCA1/2 belonging, directly or indirectly, to the HR repair pathway have been shown to sensitize tumor cells to PARP inhibition [14] and synthetic lethal-siRNA screens have identified ATM among the genes whose depletion might mediate the sensitivity to PARP inhibitors [15]. Recently, ATM-deficient mantle cell lymphoma, chronic lymphocytic leukemia, and T-prolymphocytic leukemia have been shown to be more sensitive to PARP inhibitors than ATM-proficient cells $[16,17]$ suggesting that ATM mutation/inactivation might predict responses of individual tumors to PARP inhibitors.

ATM is one of the key DNA damage sensors that have a critical role in contributing to DDR by regulating cell cycle checkpoints, DNA repair machinery, replication forks, and telomeres $[18,19]$. Homozygous mutations of ATM are responsible for ataxia-telangiectasia (A-T), a rare autosomal recessive disease mainly characterized by progressive degeneration in the cerebellum, immunodeficiency, radiosensitivity, and cancer predisposition [20,21]. Although A-T heterozygotes are usually asymptomatic and, overall considered healthy carriers, a link between single copy ATM mutations and a two to five fold risk of breast cancer has been established [22]. Recently, we have developed a straightforward, rapid, and inexpensive test to unambiguously diagnose A-T heterozygotes that would allow an easy recognition of breast cancer patients carrying monoallelic ATM germline mutations [23].

In the current studies, we assessed whether ATM depletion by RNA interference sensitize cells from breast cancer lines to PARP inhibitors. As ATM mutations and loss of ATM expression can be found in hereditary and sporadic breast cancers and A-T heterozygotes can be diagnosed [23], we hypothesized that such data might be useful in extending the molecular predictors required for selecting patients responsive to PARP inhibition.

\section{Materials and methods}

\section{Cell culture and reagents}

Human breast cancer cell lines, MCF-7 and ZR-75-1, and their transfected-derivatives were maintained in DMEMGlutamax and RPMI-Glutamax, respectively, supplemented with $10 \%$ fetal bovine serum, $100 \mathrm{U} / \mathrm{ml}$ penicillin, and
$100 \mathrm{U} / \mathrm{ml}$ streptomycin (all from Invitrogen). All cell lines were maintained in a $5 \% \mathrm{CO}_{2}$ atmosphere at $37^{\circ} \mathrm{C}$. Cells were passaged once every $3-5$ days ( $90 \%$ confluence) and all experiments were performed within the first 10 passages from transfection. For drug treatment, doxorubicin (Sigma) and PARP inhibitors, olaparib and iniparib (Selleckchem), were prepared as stock solution in water or DMSO, respectively, aliquot and stored at $-80^{\circ} \mathrm{C}$ until use.

\section{Stable knockdown of ATM in cells of breast cancer lines}

Stable interference was obtained by retroviral-mediated expression of short-hairpin RNA (shRNA) using pRETROSuper vector. Retroviruses were produced in HEK $293 \mathrm{~T}$ cells by cotransfecting pRETRO-Super together with plasmids encoding for gag-pol and VSV-G proteins. Viral supernatant was collected $48 \mathrm{hrs}$ post-transfection, filtered through a $0.45 \mu \mathrm{m}$ pore size filter and added to the cells in the presence of $2 \mu \mathrm{g} / \mathrm{ml}$ polybrene. After $48 \mathrm{hrs}$ from infection, stable polyclonal populations of control and ATM-depleted cells were obtained by selection for two weeks with $2 \mu \mathrm{g} / \mathrm{ml}$ puromycin (Sigma).

The shATM construct (\#1 position 912) in PRETROSuper, generously provided by Y. Lerenthal and Y. Shiloh, has the following sequence: $5^{\prime}$-GAC TTT GGC TGT CAA CTT TCG-3' [24]. Control shRNA, siR5, has the following sequence: 5'-GGA TAT CCC TCT AGA TTA-3'. Neither the ATM-targeting shRNA nor the control sequences have any homology with other human gene as tested by BLAST (http://blast.ncbi.nlm.nih.gov/Blast.cgi).

\section{Western blotting}

Total cell extracts were prepared in lysis buffer $[50 \mathrm{mM}$ Tris- $\mathrm{HCl} \mathrm{pH} \mathrm{8,} 300 \mathrm{mM} \mathrm{NaCl}, 1 \mathrm{mM}$ EDTA, $0.5 \%$ sodium deoxycholate, $0.1 \%$ SDS, $1 \%$ Nonidet-P40, 1 mM EDTA] supplemented with protease-inhibitor mix (Roche), resolved on precast NuPAGE 4-12\% gels (Invitrogen), and transferred onto nitrocellulose membranes (Bio-Rad). The following antibodies were employed for immunedetection: rabbit anti-ATM (Santa Cruz), mouse anti- $\alpha$-tubulin (Immunological Sciences), HRP-conjugated goat anti-mouse and anti-rabbit (Cappel). Immunoreactivity was determined using the ECL-chemiluminescence reaction (Amersham Corp) following the manufacturer's instructions.

\section{lonizing radiation (IR)}

When indicated, cells were irradiated using a ${ }^{137} \mathrm{Cs}$ source (IBL-437-C irradiator, CIS bio International) at a dose rate of $6.8 \mathrm{~Gy} / \mathrm{min}$.

\section{Citotoxicity and BrdU assays}

Cells $\left(5 \times 10^{4} / \mathrm{ml}\right)$ were seeded in 96 -well plates in growth medium and incubated $24 \mathrm{hrs}$ at $37^{\circ} \mathrm{C}$ in $5 \% \mathrm{CO}_{2}$ atmosphere. Drugs were added at the indicated concentrations and for the indicated times before incubation with reagents 
of XTT, WST-1, and BrdU (all from Roche Applied Science), following the manufacturer's instructions. The absorbance at $450 \mathrm{~nm}$ (XTT and WST-1) or at $370 \mathrm{~nm}$ (BrdU) were measured by the microplate reader Infinite F200 (Tecan). Each experiment was performed in triplicate. The survival fraction for a given dose was calculated as the plating efficiencies for that dose divided by the plating efficiencies of solvent-treated cells.

\section{Cell cycle profiles}

Treated and untreated cells $\left(5 \times 10^{5}\right)$ were washed in PBS $1 \mathrm{X}$ and resuspended in $300 \mu \mathrm{l}$ hypotonic fluorochrome solution $[50 \mu \mathrm{g} / \mathrm{ml}$ propidium iodide, $0.1 \%$ sodium citrate, $0.1 \%$ Triton-X-100 (all from Sigma)] for $30 \mathrm{~min}$ at room temperature. DNA content was measured by a FACScan flow cytometer (Becton Dickinson).

\section{Colony forming assays}

Cells were treated with drugs at the indicated doses for $24 \mathrm{hrs}$, then plated at low density in $60 \mathrm{~mm}$ Petri dishes and grown for twelve days in the absence of drugs. Surviving colonies were fixed and stained with Cristal Violet (0.5\% in methanol) (Sigma), air-dried, and counted.

\section{Statistics}

The Wilcoxon test for paired samples has been used for repeated measurements. A p-value less than $0.10\left(^{*}\right)$ and less than $0.05(* *)$ were considered statistical significant.

\section{Results and discussion}

Effects of ATM-depletion in breast cancer MCF-7 cell line

To assess the influence of ATM in breast cancer susceptibility to PARP inhibitors, we genetically repressed ATM expression by RNA interference in MCF-7 cells. We chose the MCF-7 breast cancer cell line because it is ER positive, HER2 negative, and wild-type for the BRCA1, BRCA2, and TP53 genes [25], features we observed in breast tumors arising in our A-T heterozygotes [23]. Stable interference of ATM was obtained by MCF-7 transfection with shATM-carrying vectors (MCF7-ATMi) and its siR5 negative control (MCF7-ctr) (see Materials and methods). Stable-transfected cells were selected in the presence of puromycin for ten days and maintained as polyclonal populations. As shown in Figure 1A, a strong repression of ATM expression was obtained in the MCF7-ATMi cells compared to the MCF7-ctr ones. To verify whether ATM-depletion has a functional impact on MCF-7 cells, we assessed the sensitivity of ATM-depleted and control cells to IR and doxorubicin treatment, that are known to induce different outcomes in ATM proficient and defective cells. In particular, radiosensitivity is a defining feature of ATM-defective cells [26] whereas, in a wild-type p53 context, doxorubicin-resistance was shown to characterize ATM-deficient cells in vitro [27] and in breast cancer patients [28]. As shown in Figure 1B and 1C, MCF7-ATMi cells were more sensitive to IR and more resistant to doxorubicin than MCF7-ctr cells. The contribution of ATM in the latter result was confirmed in MCF-7 parental cells by KU 55933-induced ATM inactivation (Figure 1D). These results were further confirmed by evaluating the cell cycle profiles (Figure 1E). After $24 \mathrm{hrs}$ from irradiation, both MCF7-ctr and MCF7-ATMi cells show the expected enrichment into the G2/M phase. After $48 \mathrm{hrs}$ from irradiation, MCF7-ctr cells repair the damage and re-enter into the cell cycle; in contrast, MCF7-ATMi cells, which are known to have defects in sensing and repairing DNA double strand breaks [26], show a delay in re-entering into the cell cycle. In contrast, as expected from the data reported by Jiang and co-workers [27], the ATMi cells were more resistant to doxorubicin and a lower proportion of cells underwent cell death.

Altogether, these results show that MCF-7 transduction with shATM-carrying vectors interferes with ATM expression and elicits some aspects of a phenotype compatible with ATM-deficient cells.

\section{ATM-depletion sensitizes MCF-7 cells to olaparib}

To evaluate whether ATM-depletion modifies MCF-7 response to PARP inhibitors, we first used olaparib (AZD2281, Ku-0059436), an orally bioavailable compound whose effectiveness in BRCA1/2 mutated breast and ovarian cancers was studied in phase II clinical trials and, for ovarian cancers is under further evaluation in phase III clinical studies [12]. MCF7-ATMi and MCF7-ctr cells were incubated with increasing concentrations of olaparib or its solvent (DMSO) for 72 hrs and their viability assessed by XTT or WST-1, with comparable results. As shown in Figure 2A, ATM-depleted cells were mildly but significantly more sensitive than MCF7-ctr cells to olaparib. However, MCF7-ctr cells, as well as the parental MCF-7 cells (data not shown) were not completely resistant to olaparib and their viability declined with time (Figure $2 \mathrm{~B}$ ) and at the highest doses we employed (Figure 2A, $10 \mu \mathrm{M}$ dose).

To further characterize the effect induced by olaparib, MCF7-ATMi and MCF7-ctr cells were treated for $48 \mathrm{hrs}$ with 2.5 and $5 \mu \mathrm{M}$ olaparib and their DNA content assessed by propidium iodide staining and FACS analysis. Consistently with the viability assays described above, cell death, measured by the appearance of hypodiploid cells, was detected only in the olaparib-treated MCF7-ATMi cells (Figure 2C). However, both ATM-depleted and control MCF-7 cells arrested in the $G_{2} / M$ phase of the cell cycle, in a dose-dependent manner, as previously described [2]. The similarity in the cell cycle behavior between MCF7-ATMi and MCF7-ctr cells after olaparib treatment was confirmed by BrdU assay that showed a comparable reduction in the two cell populations (Figure 2D). These data indicate that 


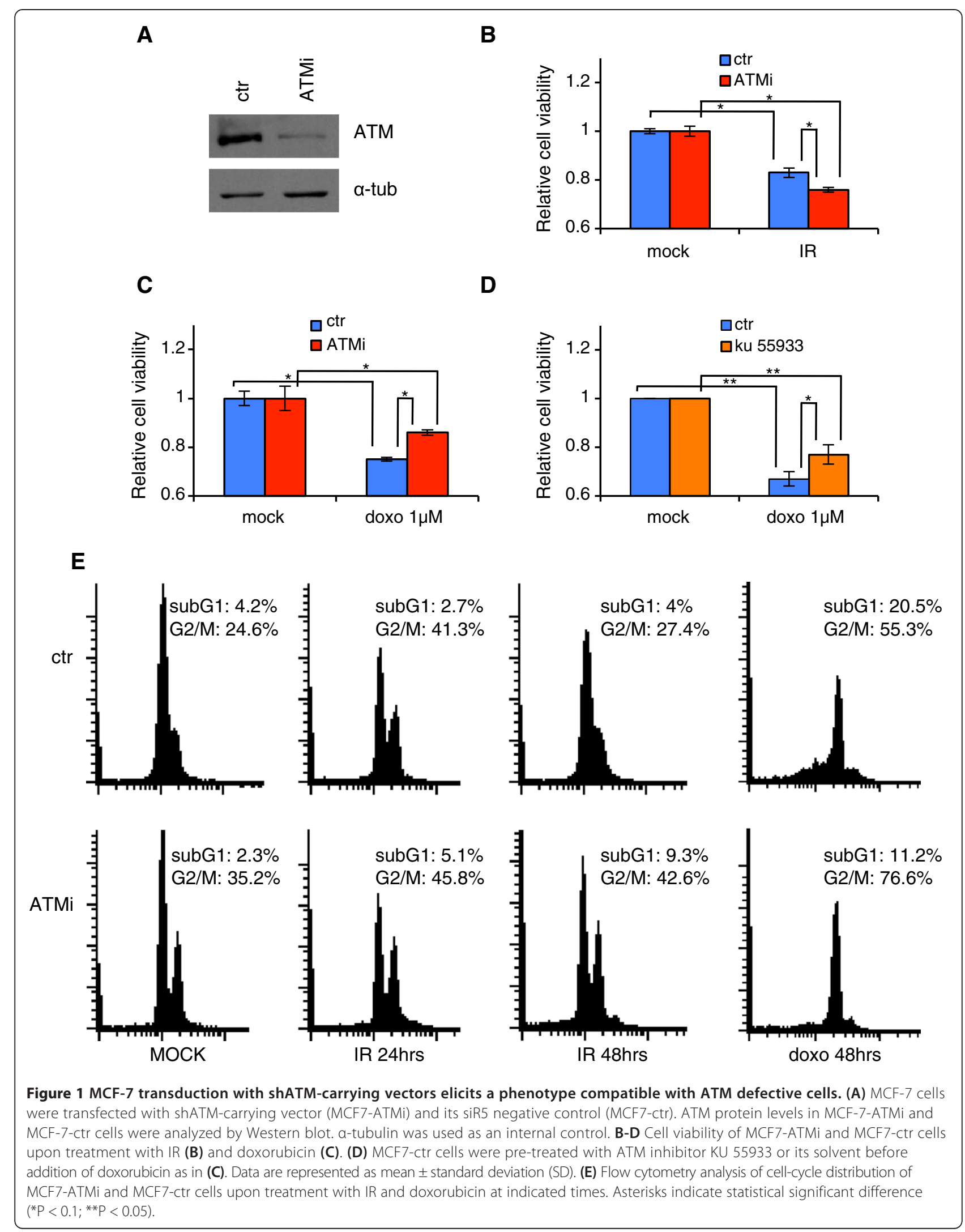




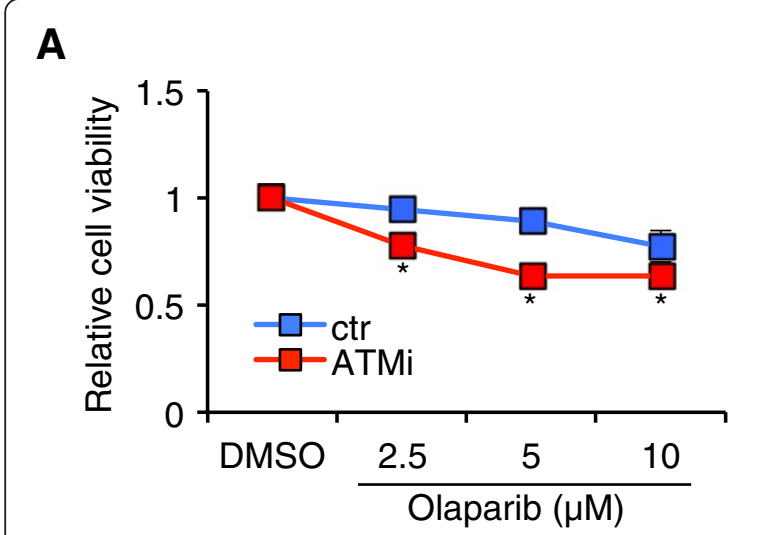

B

C
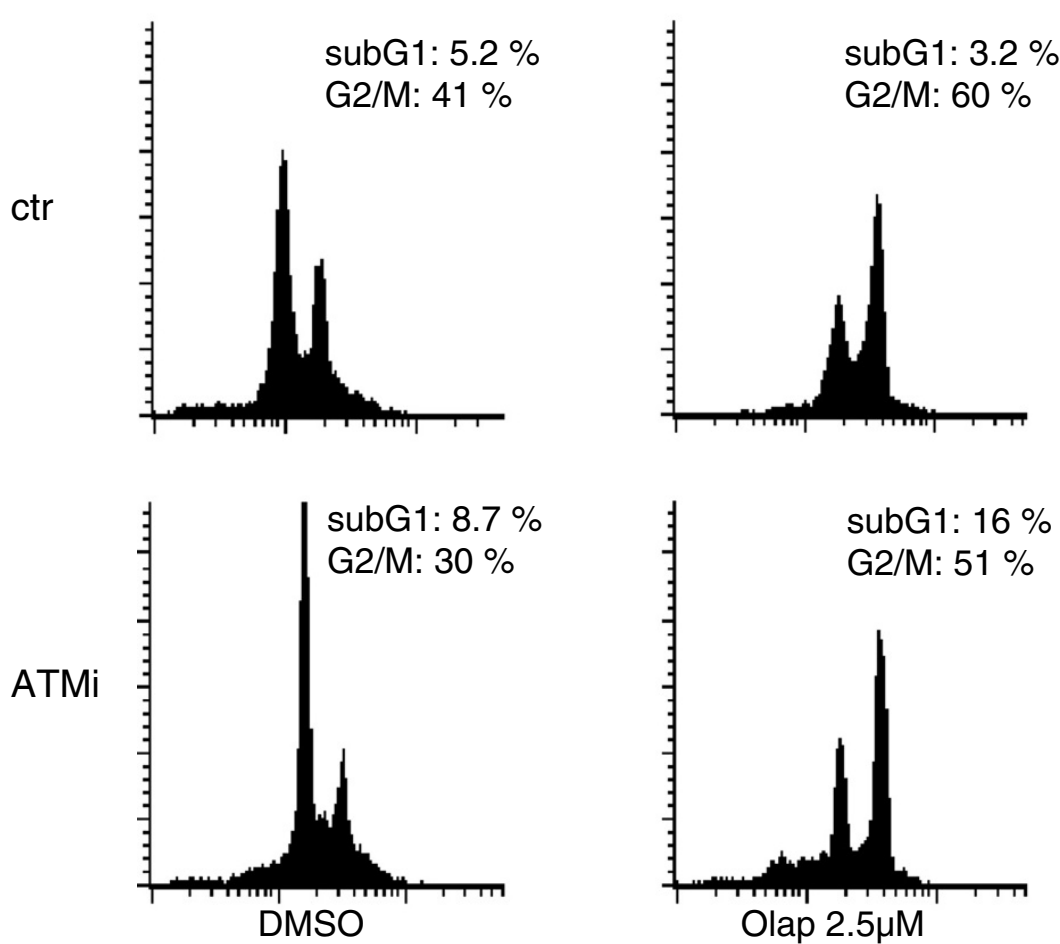

E

D

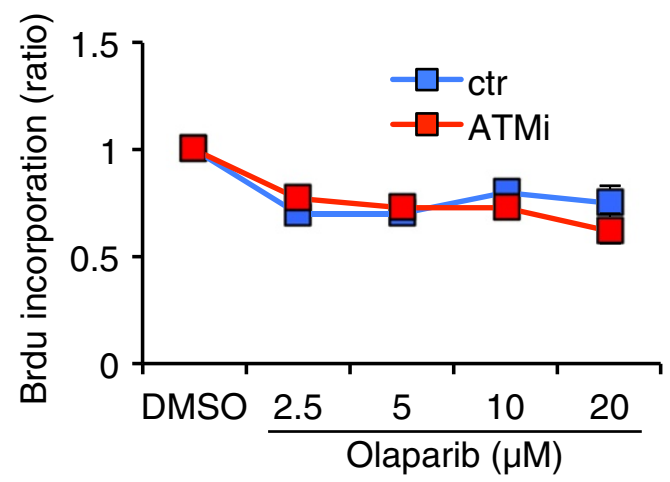

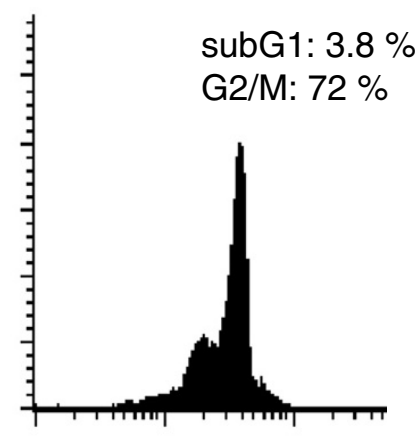

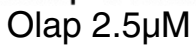
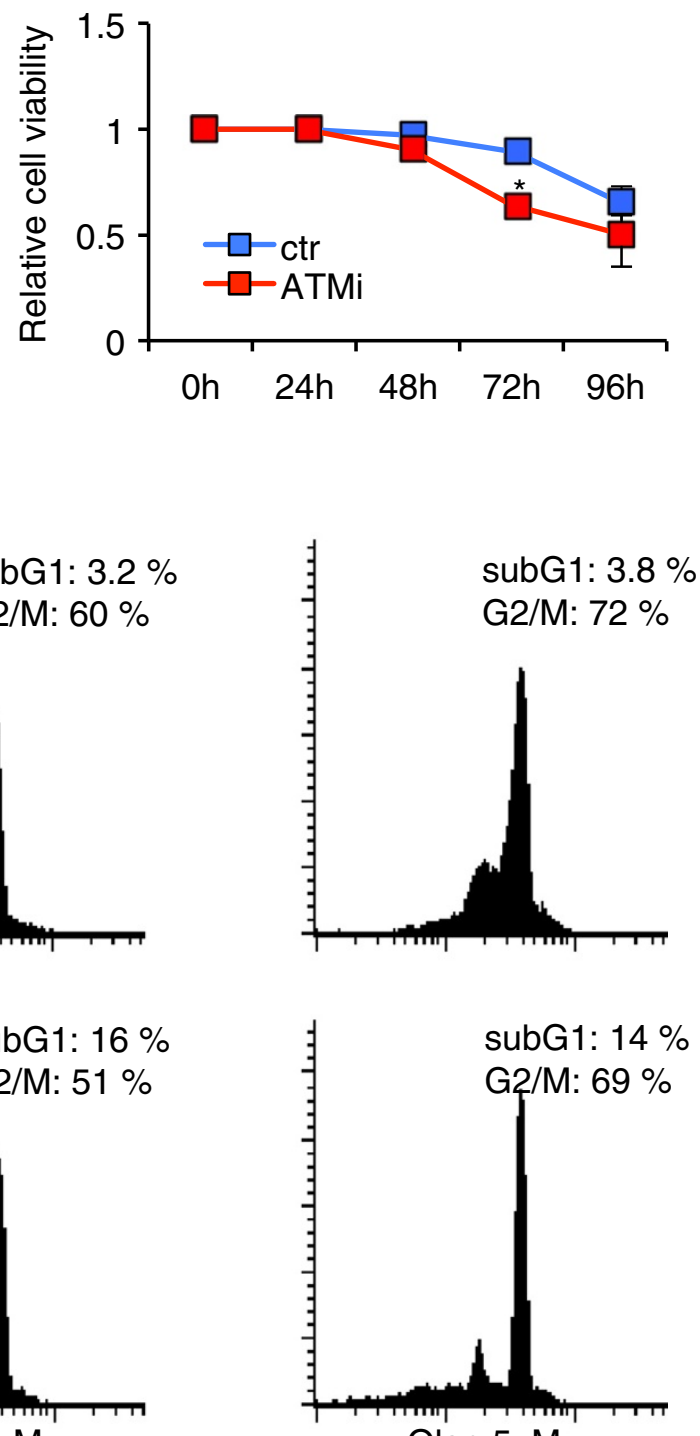

Olap $5 \mu \mathrm{M}$

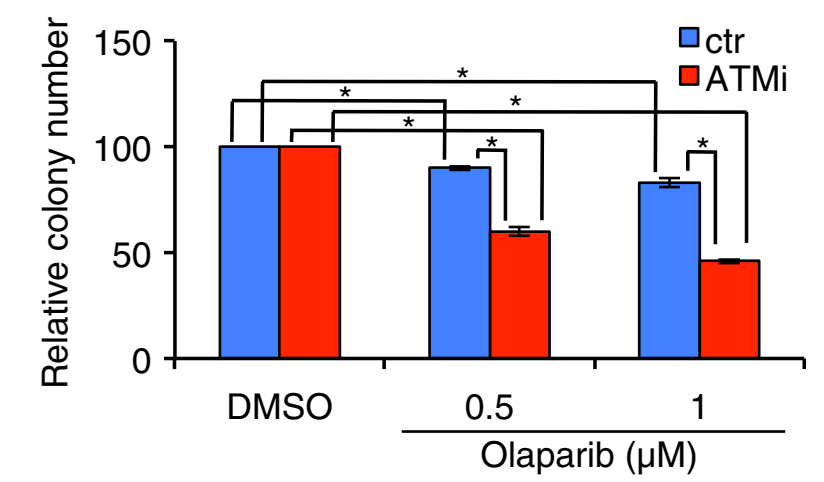

Figure 2 (See legend on next page.) 
Figure 2 MCF7-ATMi cells are more sensitive than MCF7-ctr cells to olaparib. A-B MCF7-ATMi and MCF7-ctr cells were exposed to increased concentrations of olaparib for 72 hrs (A) or were treated with olaparib (5 $\mu$ M) for up to 96 hrs (B). Data are represented as mean \pm SD. (C) Flow cytometry analysis of cell-cycle distribution of MCF7-ATMi and MCF7-ctr cells treated with the indicated concentrations with olaparib for 48 hrs.

(D) DNA synthesis was measured by BrdU incorporation assay 48 hrs after olaparib treatment. (E) Quantitative analyses of colony formation. The numbers of DMSO-resistant colonies in MCF7-ATMi and MCF7-ctr cells were set to 100, while olaparib treated cel1s were presented as mean $\pm S D$. Asterisks indicate statistical significant difference $\left({ }^{*} \mathrm{P}<0.1\right)$.

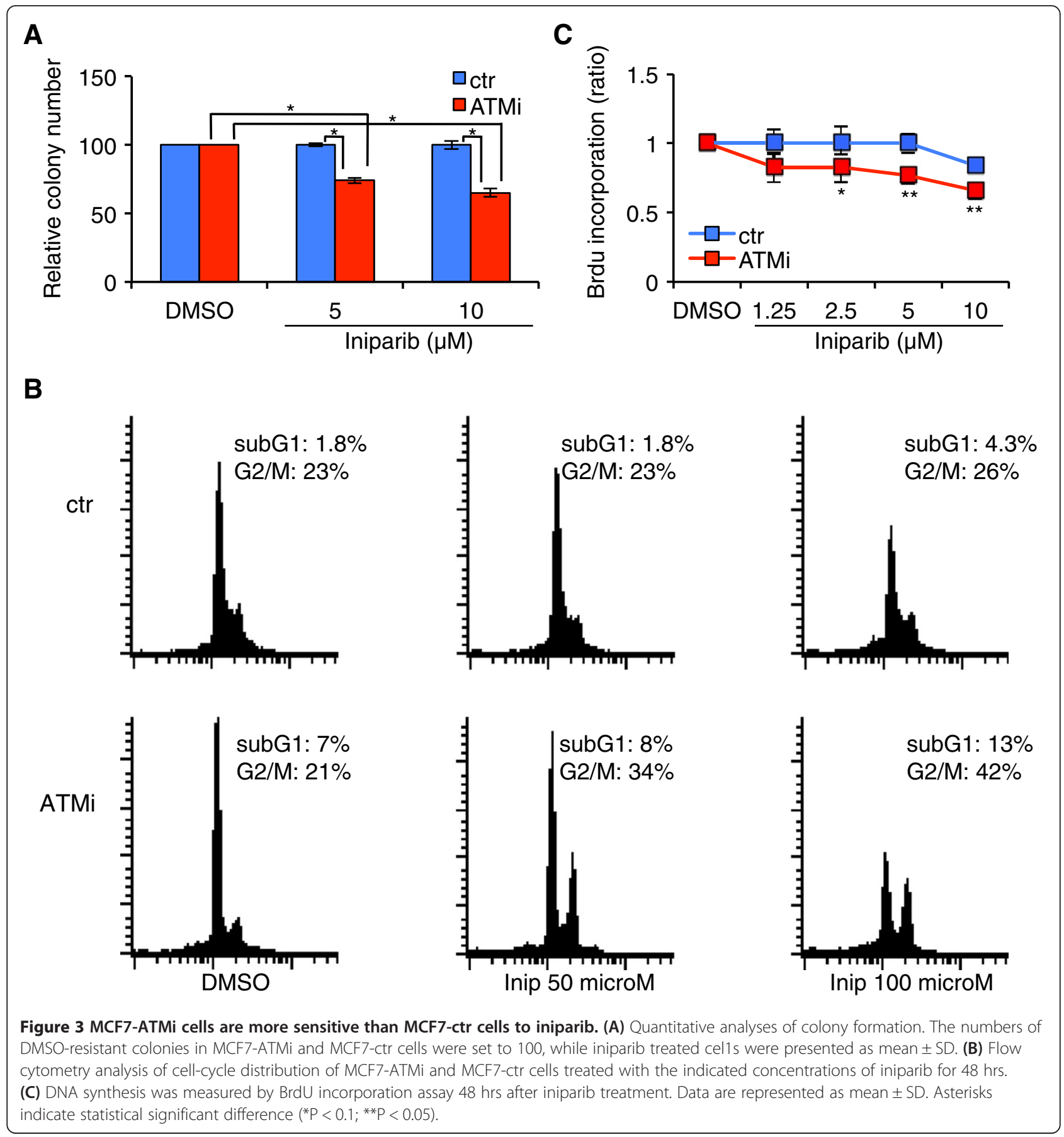




\section{A}

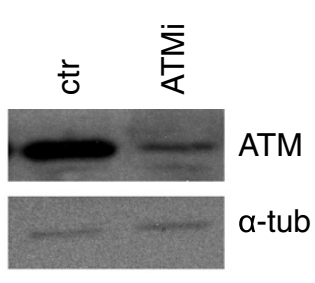

B

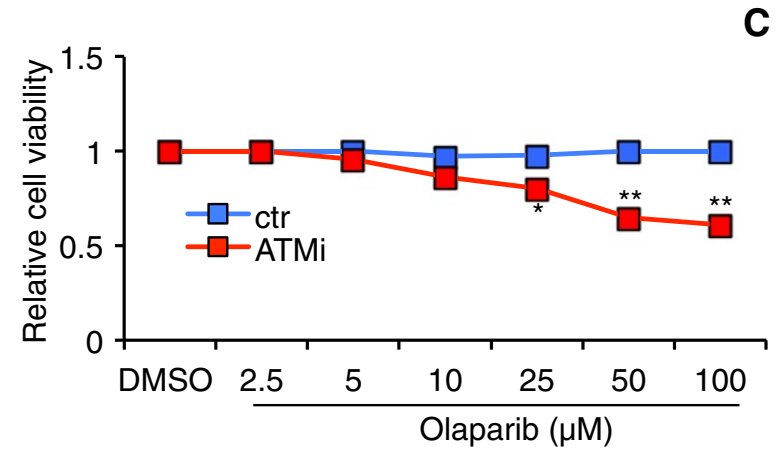

C

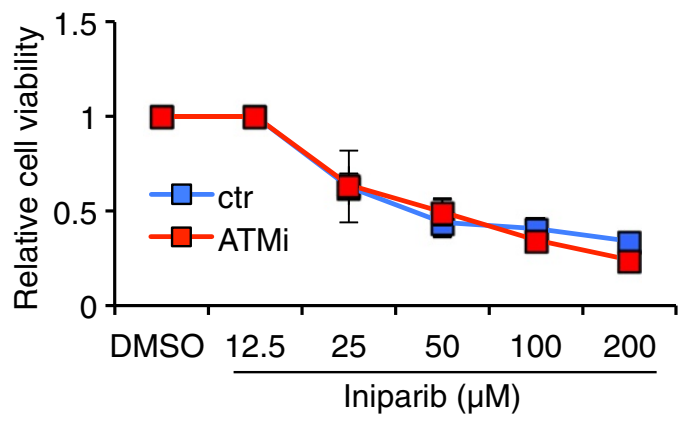

D
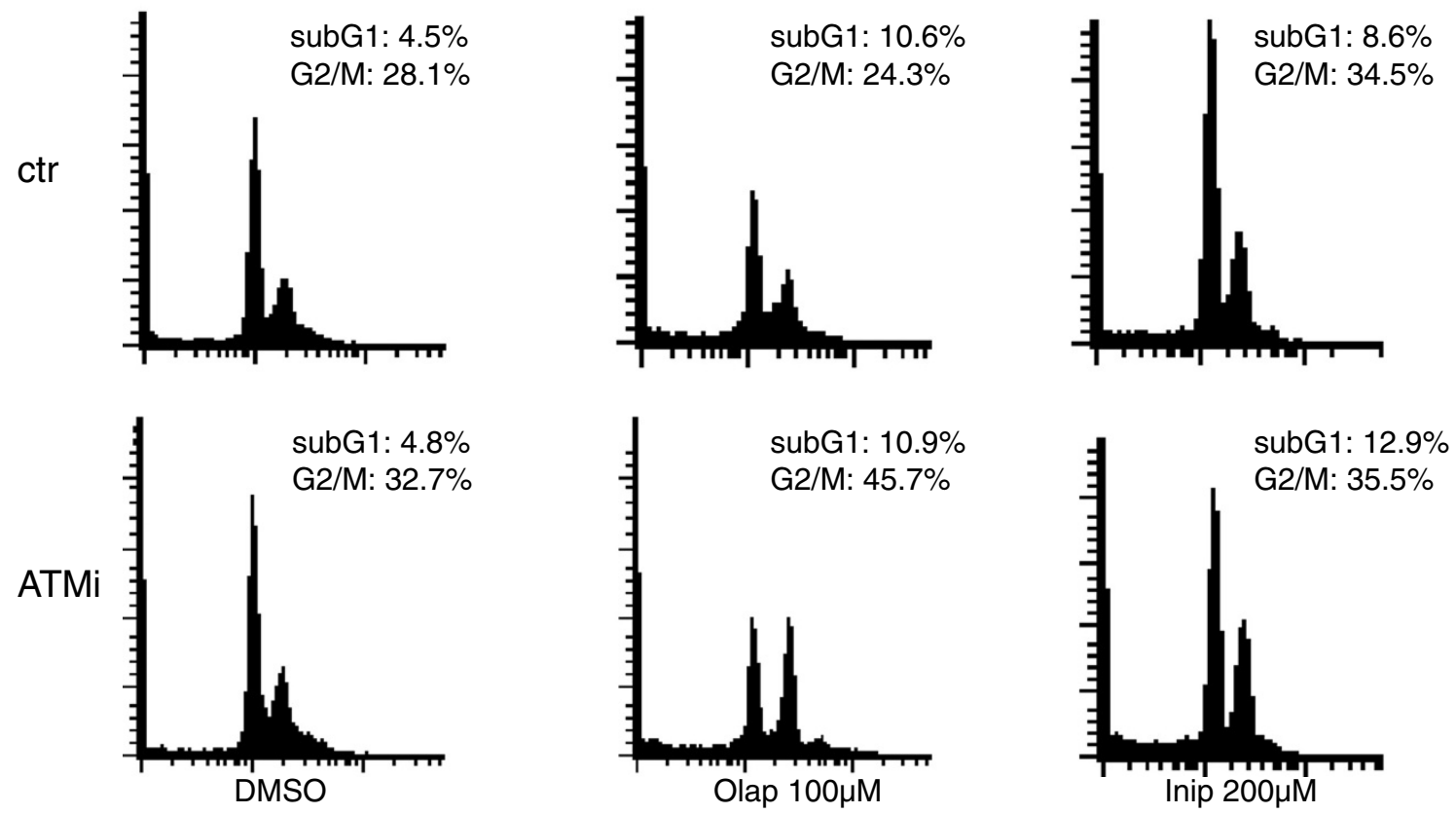

E
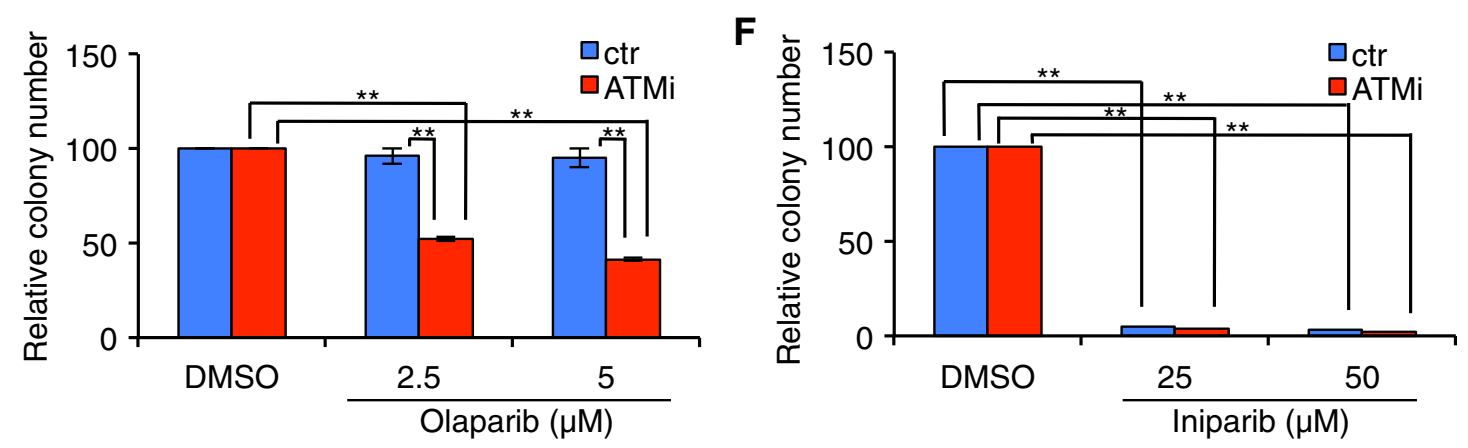

Figure 4 (See legend on next page.) 
(See figure on previous page.)

Figure 4 ZR-ATMi cells are more sensitive than ZR-ctr cells to olaparib but not to iniparib. (A) ZR-75-1 cells were transfected with shATM-carrying vector (ZR-ATMi) and its siR5 negative control (ZR-ctr). ATM protein levels in ZR-ATMi and ZR-ctr cells were analyzed by Western blot. a-tubulin was used as an internal control. B-C ZR-ATMi and ZR-ctr cells were exposed to increased concentrations of olaparib (B) or iniparib for 72 hrs (C). Data are represented as mean \pm SD. (D) Flow cytometry analysis of cell-cycle distribution of ZR-ATMi and ZR-ctr cells treated with the indicated concentrations with olaparib or iniparib for 72 hrs. E-F Quantitative analyses of colony formation. The numbers of DMSO-resistant colonies in ZR-ATMi and ZR-ctr cells were set to 100, while olaparib (E) or iniparib (F) treated cel1s were presented as mean \pm SD. Asterisks indicate statistical significant difference $\left({ }^{*} \mathrm{P}<0.1 ;{ }^{* *} \mathrm{P}<0.05\right)$.

MCF-7 sensitivity to olaparib is increased by ATMdepletion, but these cells are partially responsive to this compound, as also recently reported by others [29].

Next, we verified the long-term effect of olaparib by performing colony formation assays. MCF7-ATMi and MCF7-ctr cells were treated for 24 hrs with 0.5 and $1 \mu \mathrm{M}$ olaparib, then plated at low density and grown for twelve days in the absence of drug. As shown in Figure 2E, a significant reduction in the colony forming capacity was observed in the ATM-depleted cells compared to the controls. Consistent with the results described above, a mild reduction in colony formation was also observed in the olaparib-treated MCF7-ctr cells compared with their DMSO-treated controls (Figure 2E, blue columns).

Overall, these data indicate that ATM-depletion increases sensitivity to olaparib in breast cancer MCF-7 cells; however, factors other than ATM might contribute to the response of this cell line to this PARP-inhibitor.

\section{ATM-depletion sensitizes MCF-7 cells to iniparib}

Next, we asked whether ATM-depletion can sensitize MCF-7 cells to iniparib (BSI-201, SAR240550), a compound originally described as an irreversible inhibitor of PARP-1 [30], but recently shown to act as a nonselective modifier of cysteine-containing proteins [31,32]. MCF7ATMi and MCF7-ctr cells were treated with iniparib or its solvent, DMSO, and analyzed for colony formation capacity, DNA content by FACS analysis, and BrdU assay. As shown in Figure 3A, ATM-depletion reduced the ability of MCF-7 cells to produce colonies after iniparib-treatment while no effect was observed in MCF7-ctr cells. At variance with olaparib-treatment, DNA content analysis did not reveal any significant difference between MCF7-ATMi and MCF7-ctr cells in the appearance of hypodiploid, death cells, whereas only the MCF7-ATMi population experienced an accumulation of cells in the $\mathrm{G}_{2} / \mathrm{M}$ phase of the cell cycle (Figure $3 \mathrm{~B}$ ). This effect on the cell cycle was confirmed by BrdU assays (Figure 3C). Together, these results suggest that ATM-depletion can also influence MCF-7 cell response to iniparib.

\section{ATM-depletion sensitizes ZR-75-1 breast cancer cells to olaparib but not to iniparib}

To further assess the impact of ATM-depletion in breast cancer cell response to olaparib and iniparib, we selected the ZR-75-1 line, whose cells, like the MCF-7 ones, are ER positive, HER2 negative, and wild-type for BRCA1/2 and TP53 genes [25]. Stable interference of ATM in ZR-75-1 cells was obtained as described for MCF-7 cells. Polyclonal populations, ZR-ATMi and ZR-ctr, were obtained by puromycin selection and ATM-depletion confirmed by Western blot analysis (Figure 4A). Next, dose-response viability assays were performed on ZR-ATMi and ZR-ctr cells upon incubation with olaparib, iniparib, or their solvent, DMSO. As shown in Figures 4B, ZR-ctr cells were strongly resistant to olaparib whereas their ATM-depleted counterpart became considerably sensitive and showed a partial accumulation in the G2/M phase of the cell cycle (Figure 4D). These results, confirmed by colony formation assays (Figure 4E), sustain the observations made with MCF-7 cells and support a synthetic lethal relationship between ATM-depletion and olaparib-treatment in ER positive, wild-type BRCA $1 / 2$ breast cancer cells.

In contrast with the sensitivity induced by ATMdepletion in MCF-7 cells, when treated with iniparib, both ZR-ATMi and ZR-ctr cells showed a substantial loss of viability that was independent of ATM, as indicated by the similarity of their survival curves (Figure $4 \mathrm{C}$ ) and cell cycle distribution (Figure 4D). These results were confirmed by the complete inhibition of colony formation induced by iniparib in ZR-75-1 cells, independent of their ATM status (Figure 4F). In addition, the different response between MCF-7 and ZR-75-1 cells to this drug suggests that ER expression and the wild-type status of BRCA1/2 and TP53 are not involved in the sensitivity to iniparib. These results might be explained by the recent observations indicating that the primary mechanism of action for iniparib is a nonselective modification of cysteine-containing proteins, rather then inhibition of PARP activity [32].

\section{Conclusions}

In a few hematological malignancies, ATM-deficiency was shown to confer sensitivity to PARP inhibitors, indicating that ATM might be included in the DDR factors whose mutation or loss of expression confer sensitivity to this class of drugs. Based on these observations, we asked whether ATM deficiency plays a similar role in breast cancer, the solid tumor linked to ATM germline mutations. For this study, we employed two breast-cancer cell lines selected among those showing the molecular feature we recently 
observed in the breast tumors arising in A-T heterozygotes. In addition, we selected two compounds, olaparib and iniparib, originally described as PARP inhibitors. We show that ATM-depletion confers sensitivity to olaparib in both cell lines and a mild sensitivity to iniparib in the MCF-7 cells indicating that ATM mutation/inactivation might be consider in the selection of breast cancers responsive to PARP inhibition.

\section{Abbreviations}

ATM: Ataxia telangiectasia mutated; BRCA1/2: Breast cancer 1/2; DDR: DNA damage response; IR: Ionizing radiation; PARP: Poly(ADP-ribose) polymerase; PBS: Phosphate buffered saline; SD: Standard deviation; shRNA: Short hairpin RNA.

\section{Competing interests}

The authors declare that they have no competing interests.

\section{Authors' contributions}

MSGM and DM performed cytotoxicity and assays, clonogenicity and cell cycle profiles. AP, VS and LM performed shRNA transfection, cell selection, and western blotting. MPG and VG were responsible for cell handling. MSGM, AP, DB and SS were involved in the experimental design and conception, data collection and analysis. SS wrote the manuscript. All authors read and approved the final manuscript.

\section{Acknowledgements}

We thank Dr. Tania Merlino for the proof reading of the manuscript and Dr. Lidia Strigari for statistical support. This work was supported by grants from Associazione Italiana per la Ricerca sul Cancro (AIRC) to S.S. (IG10568) and D. B. (10590), from Ministero della Salute to V.S. (GR 10.120), and from Ministero dell'Istruzione, dell'Università e della Ricerca to D.B. (Prin). These funders had no role in study design, data collection and analysis, decision to publish, or preparation of the manuscript.

\section{Author details}

${ }^{1}$ Department of Ecological and Biological Sciences, Tuscia University, Largo dell'Università, 01100 Viterbo, Italy. ${ }^{2}$ Experimental Oncology, Regina Elena National Cancer Institute, Via Elio Chianesi, 53-00144 Rome, Italy. ${ }^{3}$ Laboratory of Cell Signaling, IRCCS-Fondazione Santa Lucia, Via Ardeatina 306, 00179 Rome, Italy. "Department of Biology, University of Rome "Tor Vergata", Via della Ricerca Scientifica, 00133 Rome, Italy.

Received: 29 August 2013 Accepted: 14 November 2013 Published: 19 November 2013

\section{References}

1. Bryant HE, Schultz N, Thomas HD, Parker KM, Flower D, Lopez E, Kyle S, Meuth M, Curtin NJ, Helleday T: Specific killing of BRCA2-deficient tumours with inhibitors of poly(ADP-ribose) polymerase. Nature 2005, 434(7035):913-917.

2. Farmer H, McCabe N, Lord CJ, Tutt AN, Johnson DA, Richardson TB, Santarosa M, Dillon K, Hickson I, Knights C, Martin NM, Jackson SP, Smith GC, Ashworth A: Targeting the DNA repair defect in BRCA mutant cells as a therapeutic strategy. Nature 2005, 434(7035):917-921.

3. Dobzhansky T: Genetics of natural populations. Xiii. Recombination and variability in populations of Drosophila Pseudoobscura. Genetics 1946, 31(3):269-290

4. Lucchesi JC: Synthetic lethality and semi-lethality among functionally related mutants of Drosophila melanogaster. Genetics 1968, 59(1):37-44.

5. Hartwell LH, Szankasi P, Roberts CJ, Murray AW, Friend SH: Integrating genetic approaches into the discovery of anticancer drugs. Science 1997, 278(5340):1064-1068.

6. Kaelin WG Jr: The concept of synthetic lethality in the context of anticancer therapy. Nat Rev Cancer 2005, 5(9):689-698.

7. Rehman FL, Lord CJ, Ashworth A: Synthetic lethal approaches to breast cancer therapy. Nat Rev Clin Oncol 2010, 7(12):718-724.

8. Fong PC, Boss DS, Yap TA, Tutt A, Wu P, Mergui-Roelvink M, Mortimer P, Swaisland H, Lau A, O'Connor MJ, Ashworth A, Carmichael J, Kaye SB, Schellens $J$, de Bono JS: Inhibition of poly(ADP-ribose) polymerase in tumors from BRCA mutation carriers. N Engl J Med 2009, 361 (2):123-134.
9. Tutt A, Robson M, Garber JE, Domchek SM, Audeh MW, Weitzel JN, Friedlander M, Arun B, Loman N, Schmutzler RK, Wardley A, Mitchell G, Earl $\mathrm{H}$, Wickens M, Carmichael J: Oral poly(ADP-ribose) polymerase inhibitor olaparib in patients with BRCA1 or BRCA2 mutations and advanced breast cancer: a proof-of-concept trial. Lancet 2010, 376(9737):235-244.

10. Gelmon KA, Tischkowitz M, Mackay H, Swenerton K, Robidoux A, Tonkin K, Hirte H, Huntsman D, Clemons M, Gilks B, Yerushalmi R, Macpherson E, Carmichael J, Oza A: Olaparib in patients with recurrent high-grade serous or poorly differentiated ovarian carcinoma or triple-negative breast cancer: a phase 2, multicentre, open-label, non-randomised study. Lancet Oncol 2011, 12(9):852-861.

11. Balmaña J, Domchek SM, Tutt A, Garber JE: Stumbling blocks on the path to personalized medicine in breast cancer: the case of PARP inhibitors for BRCA1/2-associated cancers. Cancer Discov 2011, 1(1):29-34.

12. Davar $\mathrm{D}$, Beumer $\mathrm{JH}$, Hamieh $\mathrm{L}$, Tawbi H: Role of PARP inhibitors in cancer biology and therapy. Curr Med Chem 2012, 19(23):3907-3921.

13. Lord CJ, Ashworth A: The DNA damage response and cancer therapy. Nature 2012, 481(7381):287-294.

14. McCabe N, Turner NC, Lord CJ, Kluzek K, Bialkowska A, Swift S, Giavara S, O'Connor MJ, Tutt AN, Zdzienicka MZ, Smith GC, Ashworth A: Deficiency in the repair of DNA damage by homologous recombination and sensitivity to poly (ADP-ribose) polymerase inhibition. Cancer Res 2006, 66(16):8109-8115.

15. Turner NC, Lord CJ, lorns E, Brough R, Swift S, Elliott R, Rayter S, Tutt AN, Ashworth A: A synthetic lethal siRNA screen identifying genes mediating sensitivity to a PARP inhibitor. EMBO J 2008, 27(9):1368-1377.

16. Williamson CT, Muzik H, Turhan AG, Zamò A, O'Connor MJ, Bebb DG, Lees-Miller SP: ATM deficiency sensitizes mantle cell lymphoma cells to poly(ADP-ribose) polymerase-1 inhibitors. Mol Cancer Ther 2010, 9(2):347-357.

17. Weston VJ, Oldreive CE, Skowronska A, Oscier DG, Pratt G, Dyer MJ, Smith G, Powell JE, Rudzki Z, Kearns P, Moss PA, Taylor AM, Stankovic T: The PARP inhibitor olaparib induces significant killing of ATM-deficient lymphoid tumor cells in vitro and in vivo. Blood 2010, 116(22):4578-4587.

18. Derheimer FA, Kastan MB: Multiple roles of ATM in monitoring and maintaining DNA integrity. FEBS Lett 2010, 584(17):3675-3681.

19. Bensimon A, Aebersold R, Shiloh Y: Beyond ATM: the protein kinase landscape of the DNA damage response. FEBS Lett 2011, 585(11):1625-1639.

20. Shiloh Y: Ataxia-telangiectasia and the Nijmegen breakage syndrome: related disorders but genes apart. Annu Rev Genet 1997, 31:635-662.

21. Lavin MF: Ataxia-telangiectasia: from a rare disorder to a paradigm for cell signalling and cancer. Nat Rev Mol Cell Biol 2008, 9(10):759-769.

22. Shuen AY, Foulkes WD: Inherited mutations in breast cancer genes-risk and response. J Mammary Gland Biol Neoplasia 2011, 16(1):3-15.

23. Prodosmo A, De Amicis A, Nisticò C, Gabriele M, Di Rocco G, Monteonofrio L, Piane M, Cundari E, Chessa L, Soddu S: p53 centrosomal localization diagnoses ataxia-telangiectasia homozygotes and heterozygotes. J Clin Invest 2013, 123(3):1335-1342.

24. Biton S, Dar I, Mittelman L, Pereg Y, Barzilai A, Shiloh Y: Nuclear ataxia-telangiectasia mutated (ATM) mediates the cellular response to DNA double strand breaks in human neuron-like cells. J Biol Chem 2006, 281(25):17482-17491.

25. Kao J, Salari K, Bocanegra M, Choi YL, Girard L, Gandhi J, Kwei KA, Hernandez-Boussard T, Wang P, Gazdar AF, Minna JD, Pollack JR: Molecular profiling of breast cancer cell lines defines relevant tumor models and provides a resource for cancer gene discovery. PLoS One 2009, 4(7):e6146.

26. Shiloh Y: The ATM-mediated DNA-damage response: taking shape. Trends Biochem Sci 2006, 31(7):402-410.

27. Jiang H, Reinhardt HC, Bartkova J, Tommiska J, Blomqvist C, Nevanlinna H, Bartek J, Yaffe MB, Hemann MT: The combined status of ATM and p53 link tumor development with therapeutic response. Genes Dev 2009, 23(16):1895-1909.

28. Knappskog S, Chrisanthar R, Løkkevik E, Anker G, Østenstad B, Lundgren S, Risberg T, Mjaaland I, Leirvaag B, Miletic H, Lønning PE: Low expression levels of ATM may substitute for CHEK2/TP53 mutations predicting resistance towards anthracycline and mitomycin chemotherapy in breast cancer. Breast Cancer Res 2012, 14(2):R47.

29. Daemen A, Wolf DM, Korkola JE, Griffith OL, Frankum JR, Brough R, Jakkula LR, Wang NJ, Natrajan R, Reis-Filho JS, Lord CJ, Ashworth A, Spellman PT, Gray JW, Van't Veer $\sqcup$ : Cross-platform pathway-based analysis identifies markers of response to the PARP inhibitor olaparib. Breast Cancer Res Treat 2012, 135(2):505-517. doi: 10.1007/s10549-012-2188-0. Epub 2012 Aug 9. 
30. Mendeleyev J, Kirsten E, Hakam A, Buki KG, Kun E: Potential chemotherapeutic activity of 4-iodo-3-nitrobenzamide. Metabolic reduction to the 3-nitroso derivative and induction of cell death in tumor cells in culture. Biochem Pharmacol 1995, 50(5):705-714.

31. Patel AG, De Lorenzo SB, Flatten KS, Poirier GG, Kaufmann SH: Failure of iniparib to inhibit poly(ADP-Ribose) polymerase in vitro. Clin Cancer Res 2012, 18(6):1655-1662.

32. Liu X, Shi Y, Maag DX, Palma JP, Patterson MJ, Ellis PA, Surber BW, Ready DB, Soni NB, Ladror US, Xu AJ, lyer R, Harlan JE, Solomon LR, Donawho CK, Penning TD, Johnson EF, Shoemaker AR: Iniparib nonselectively modifies cysteine-containing proteins in tumor cells and is not a bona fide PARP inhibitor. Clin Cancer Res 2012, 18(2):510-523.

doi:10.1186/1756-9966-32-95

Cite this article as: Gilardini Montani et al: ATM-depletion in breast

cancer cells confers sensitivity to PARP inhibition. Journal of Experimental \& Clinical Cancer Research 2013 32:95.

\section{Submit your next manuscript to BioMed Central and take full advantage of:}

- Convenient online submission

- Thorough peer review

- No space constraints or color figure charges

- Immediate publication on acceptance

- Inclusion in PubMed, CAS, Scopus and Google Scholar

- Research which is freely available for redistribution 